\title{
Prisma VLC Dycal
}

National Cancer Institute

\section{Source}

National Cancer Institute. Prisma VLC Dycal. NCI Thesaurus. Code C86581.

A proprietary light-cured, calcium hydroxide and resin cavity liner. 